DOI: http://dx.doi.org/10.11144/Javeriana.upsy16-1.iecs

\title{
Identidad étnica y conductas sociales en adolescentes indígenas mapuche sancionados por la Ley de Responsabilidad Penal Adolescente en regiones del sur de Chile*
}

Ethnic Identity and Social Behaviors in Indigenous Juvenile Offenders Sentenced by the Law in the South of Chile

\author{
Raúl Alberto Jiménez Bustos ${ }^{\mathrm{a}}$ \\ Universidad de la Frontera, Chile \\ Ricardo Xavier Pérez-Luco Arenas ${ }^{b}$ \\ Universidad de la Frontera, Chile \\ ORCID: http://orcid.org/0000-0002-7051-5005 \\ Gonzalo Eugenio Bustamante \\ RIVERA \\ Universidad de la Frontera, Chile
}

\footnotetext{
a Magíster en Psicología Jurídica y Forense

b Autor de correspondencia. Correo electrónico: ricardo.perez-luco@ufrontera.cl
}

Para citar este artículo: Jiménez Bustos, R. A., PérezLuco Arenas, R. X., \& Bustamante Rivera, G. E. (2017). Identidad étnica y conductas sociales en adolescentes indígenas mapuche sancionados por la Ley de Responsabilidad Penal Adolescente en regiones del sur de Chile. Universitas Psychologica, 16(1), 1-22. http://dx.doi.org/10.11144/Javeriana.upsy16-1.iecs

\section{RESUMEN}

Se analiza la relación entre identidad étnica y conductas sociales en 60 adolescentes indígenas infractores de ley autoidentificados como mapuche. La identidad étnica se obtiene con la Escala IEM; conductas sociales, con CACSA; delitos autorreportados, con EDA y judicializados, con Ficha FER-R. El objetivo fue evaluar la asociación entre grado de desarrollo de identidad étnica con presencia de conductas antisociales y prosociales. Los resultados indican que a mayor desarrollo de identidad étnica menor presencia de conductas antisociales, no observándose relación entre identidad étnica y conductas prosociales. Se discute la relevancia de la identidad étnica como factor protector específico en adolescentes infractores mapuche y en adolescentes de otros pueblos indígenas en general, convirtiéndose en posible foco de intervención para desestimar estas conductas.

Palabras clave

adolescencia; identidad étnica mapuche; conductas antisociales; justicia juvenil; riesgos; factores protectores.

\begin{abstract}
We examined the relationship between ethnic identity and social behaviors in 60 indigenous juvenile offenders self-identified as mapuche. Ethnic identity is obtained with IEM scale, social behaviors with CACSA, self-reported and sentenced offenses with EDA and FER-R. The objective was to evaluate the association between the degree of ethnic identity development with presence of antisocial and prosocial behavior. The results indicate that ethnic identity development was related to lesser presence of antisocial behaviors, though no relationship between ethnic identity and prosocial behaviors. The possible relevance of ethnic identity as a protective factor in mapuche youth offenders in specific and in general
\end{abstract}


to adolescents of other indigenous people, becoming a possible focus of intervention to dismiss these behaviors is discussed.

Keywords

adolescence; mapuche ethnic identity; social behavior; youth justice; risk; protective factors.

\section{Introducción}

\section{Contextualización}

En Chile, la incorporación del pueblo mapuche al interior del Estado se realizó mediante lo que la historiografía oficial llama "Pacificación de la Araucanía”, desde mediados del siglo XIX hasta 1880. A partir de este proceso - de tipo militar-, de anexión del territorio mapuche, la sociedad chilena ha impulsado la asimilación de los mapuche al interior de la sociedad. Este proceso se caracterizó por utilizar estrategias violentas que terminaron con la creación de reducciones indígenas, la militarización y despojo de sus tierras y los intentos de eliminar aspectos propios de la cultura mapuche (Correa \& Mella, 2010).

En la actualidad, los efectos de la "Pacificación de la Araucanía" han generado procesos de marginalización en el pueblo mapuche, como formas de exclusión social, impactando negativamente en diversos ámbitos. Por una parte, económicamente, se ha observado que del total de mapuche (604.349) que vivían en el país en el 2002, el 33 \% habitaba en la Región de la Araucanía y un tercio de ellos se encontraba bajo la línea de la pobreza (Agostini, Brown, \& Román, 2010). Por otra parte, se reportan bajos niveles de escolarización, específicamente, entre la educación básica y media, el $30 \%$ de los niños mapuche abandonan la escuela (Instituto Nacional de Estadísticas [INE], 2002). Esto último se explica en parte a que muchos jóvenes comienzan a trabajar para apoyar a sus padres en tareas del mantenimiento del hogar y participar en siembras y cosechas, entre otras actividades (Organización Internacional del Trabajo [OIT], 2006).

Asimismo, los procesos migratorios de los mapuche, se han dirigido desde los espacios rurales, reducidos en el siglo XIX, hacia a los urbanos; migración que es mayor en estos que en otros pueblos originarios. A pesar de la idea de que a mayor contacto con sectores urbanos mayor bienestar socioeconómico, se ha observado que en los mapuche la pobreza en los sectores urbanos es mayor que en los rurales (Agostini et al., 2010), generando asî condiciones vulnerables para el núcleo familiar, facilitando procesos de aculturación más fuertes, desvinculando a los integrantes de la familia del territorio como también perdiendo el uso de la lengua y las tradiciones.

Relacionado con lo anterior, un aspecto central que amplifica y reproduce la exclusión social es el no reconocimiento a los mapuche, por parte del Estado chileno, del estatus de pueblo (Correa \& Mella, 2010), lo que implica negar el sentido de identidad, y por ende negar la posibilidad de ser un pueblo diferente compartiendo un espacio territorial común con el resto de la sociedad chilena.

Como consecuencia de lo anterior, en la esfera social, se ha construido una imagen de los mapuche basada en estereotipos negativos (Saiz, Rapimán, \& Mladinic, 2008), provocando que muchos de ellos lleguen a autoevaluarse a través de estos (Saiz, Merino, \& Quilaqueo, 2009), lo que deriva en negar su identidad, desvalorizarla y desvincularse de ella, generando conflictos y tensiones en los individuos respecto a su pueblo originario. Considerando este contexto de vulnerabilidad, marginalización, estigmatización y pobreza, es de especial interés para este artículo observar los procesos de conformación de la identidad de los adolescentes mapuche y su relación con las conductas sociales.

Específicamente, la adolescencia se entiende como el período cuando los jóvenes se enfrentan a la tarea de resolver su identidad (Erikson, 1968); en el caso de los adolescentes mapuche, se ven no solo desafiados a resolver su identidad personal, sino además a evaluar la identificación con su cultura de origen que está posicionada en desventaja con la cultura dominante (Schwartz, Zamboanga, \& Hernández, 2007). Este proceso identitario "dual" se despliega en un contexto altamente desfavorable, donde además las 
tensiones psicosociales propias de la adolescencia pueden provocar la aparición de conductas desadaptativas y/o delictivas.

Estas conductas, a nivel psicológico, pueden comprenderse como estrategias de adaptación mientras se resuelve la identidad, pero también como de sobrevivencia ante este contexto (Alarcón, Vinet, \& Salvo, 2005). Sin embargo, en un estudio donde se analizó la capacidad mediadora de la autoestima entre la relación de la identidad étnica y las conductas externalizadoras en adolescentes turco-daneses y marroquíesdaneses, se observó que en este último grupo un mayor desarrollo de la identidad étnica se relacionaba con una mayor autoestima, y esta última con un menor grado de conductas externalizantes (Wissinka, Dekovic, Sengu, Stamsb, \& de Haana, 2008). En otras palabras, una identificación definida hacia la cultura de origen puede funcionar como un factor que atenúe la existencia de conductas desadaptativas.

\section{Adolescencia y conductas antisociales}

Como se mencionó anteriormente, la adolescencia surge como un período característico de conformación de la identidad; a su vez, en este período, se observa un aumento en el riesgo de conductas antisociales (Farrington, 1996). Específicamente, el concepto de conductas antisociales alude a una diversidad de actos que violan las normas sociales y los derechos de los otros (Kazdin \& Buela-Casal, 2002). Adicionalmente, se ha argumentado que la conducta antisocial va desde conductas agresivas y problemas con los pares, hasta robos y quebrantamientos a las normas de convivencia social en diversos contextos socializadores (Peña $\&$ Graña, 2006).

Muchas de estas conductas antisociales se convierten en conductas que infringen la ley, dado que en la legislación se tipifican como delito, sin embargo, las sanciones son específicas para este grupo etario. En Chile, entre 1986 y 2002, la cantidad de jóvenes infractores menores de 18 años que fueron aprehendidos por la policía aumentó en un 369 \% (Méndez \&
Barra, 2008); y para el año 2010, las dos regiones del sur de Chile, donde se realiza este estudio (La Araucanía y Los Ríos), sumaban 1435 los adolescentes sancionados bajo la ley de responsabilidad penal, $91 \%$ de los cuales eran hombres (Servicio Nacional de Menores [SENAME], 2010), llegando a un $2.7 \%$ del total de la población adolescente de ambas regiones para ese año (INE, 2014).

Se han descrito ampliamente dos formas de delincuencia adolescente: una común o transitoria, caracterizada por conductas delictivas pasajeras, asociadas al proceso adolescente y que desiste de forma natural con el tiempo, representando entre el 68 \% (Solís, Alvarado, \& Pérez-Luco, 2015) y el 95 \% (Fréchette \& Le Blanc, 1998) de la delincuencia adolescente; y otra forma, denominada persistente o distintiva, que representa entre el $5 \%$ y el $28 \%$ de los adolescentes que delinquen, haciéndolo desde temprana edad (inicio previo a la adolescencia), con gran volumen de delitos de diverso tipo, alta frecuencia, gravedad creciente $y$ proyección hacia la vida adulta (Le Blanc, Còte, \& Loëber, 1991; Fabio, Tu, Loëber, \& Cohen, 2011; Fréchette \& Le Blanc, 1998; Loëber \& Farrington, 2001; Moffitt, 1993; Pérez-Luco et al., 2014; Piquero \& Moffitt, 2005). En este grupo, se han identificado trayectorias diferenciadas que se expresan en patrones de conducta delictiva distintivos, en contextos de riesgo criminógeno específicos y con configuraciones de personalidad características (Alarcón, 2015; Alarcón et al., 2014; Fréchette \& Le Blanc, 1998; Pérez-Luco, Lagos, \& Báez, 2012).

En Chile, el SENAME ha adoptado un modelo de intervención que busca la reinserción social de los adolescentes infractores de ley, $y$ se fundamenta en un paradigma de justicia restaurativa, entendida como la opción de una justicia orientada a reparar el daño social, individual y relacional causado por el delito cometido (Ward \& Langlands, 2009). De esta forma, se considera que un aspecto esencial es poder detectar y modificar los factores de riesgo y protección hacia la conducta antisocial 
y delictiva. Desde esta perspectiva, diversos autores han identificado múltiples factores que predisponen hacia conductas antisociales, así como también la prevención o disminución de estas.

Se ha observado que, a nivel familiar, la presencia de estilos parentales negligentes y autoritarios se asocian a mayor presencia de conductas antisociales y delictivas (Hoeve et al., 2008), al efecto de vivir en contexto de pobreza de forma prolongada (Eamon \& Mulder, 2005), a la influencia de los pares (Monahan, Cauffman, \& Steinberg, 2009), al rechazo de los pares y a la conducta agresiva previa (Coie, Terry, Lenox, Lochman, \& Hyman, 1995).

En Chile, a partir de un proyecto de colaboración con la Universidad de Quebec en Outaouais y un posterior proyecto de investigación aplicada financiado por el Consejo Nacional de Ciencia y Tecnología, CONICYT (Pérez-Luco, Alarcón, Zambrano, Bustamante, \& Alarcón, 2009), se cuenta con metodologías que permiten evaluar la presencia de conductas antisociales y sus factores de riesgo y protección en adolescentes. Sin embargo, aún existen particularidades que no han sido investigadas; específicamente, si consideramos que algunos adolescentes infractores de ley proceden de diversos pueblos originarios, se hace necesario estudiar el rol que juegan aspectos culturales que no han sido abordados. En particular, al estudiar a adolescentes pertenecientes al pueblo mapuche, uno de los elementos diferenciadores sería integrar aspectos del desarrollo de la identidad étnica como factor de riesgo o protección hacia la presencia y persistencia de conductas antisociales.

\section{Identidad étnica en la adolescencia}

El concepto de identidad es complejo, desde la psicología puede entenderse como una referencia a lo idiosincrático de un individuo, al modo en que la persona se autoidentifica con rasgos personales o en referencia con otros (Northoff \& Heinzel, 2003); pero también, desde el punto de vista antropológico, se entiende como el sentido de pertenencia a una colectividad, a un grupo específico de referencia, el cual es evaluado por el propio sujeto (Van Meijl, 2008).

Este estudio, se basó en la teoría del desarrollo de la identidad étnica en la adolescencia planteada por Phinney (1989), la cual señala que se trata de un proceso caracterizado por la búsqueda de la identidad, donde surge la necesidad de integrar la percepción de sí mismo, la identidad impuesta por la familia y la sociedad (French, Seidman, Allen, \& Aber, 2006), siendo un proceso de internalización autoconstruida del significado de pertenencia a un grupo étnico, el cual se acompaña de reacciones emocionales, pensamientos y acciones (Lerner \& Steinberg, 2009). A partir de lo anterior, Phinney (1989) plantea un modelo que se focaliza en las sucesivas transformaciones de esta etapa, donde la formación de la identidad comprende dos dimensiones que interactúan: la de exploración, que se asocia con procesos de aprendizaje, resultado del buscar información y experimentar vivencias asociadas con la propia cultura y la de afirmación, que se refiere a la vinculación afectiva, caracterizada por sentimientos y emociones que surgen hacia el grupo.

Del resultado de la interacción de ambas dimensiones, el autor explicita que se pueden establecer etapas del desarrollo en la adolescencia. Por una parte, existe un período de identidad étnica difusa, donde los adolescentes carecen de una visión positiva o negativa de su grupo étnico, es decir, no existe una vinculación afectiva con el grupo, como tampoco han explorado el significado de esta. Por otra parte, aparece una etapa denominada moratoria, donde comienzan a explorar lo que significa ser miembro de un grupo, pero sin tener aún una vinculación afectiva clara que permita valorar la relación de él mismo con el grupo, en términos afectivos. Así también, se da una etapa denominada delegación, que consiste en identificarse afectivamente, pero sin una mayor comprensión de lo que significa pertenecer a un grupo étnico específico, es decir, hay sentimientos hacia el grupo, pero que no se fundamentan en la comprensión de la cultura resultado de una búsqueda activa por 
parte del adolescente. Finalmente, se encuentra una etapa denominada realizada, caracterizada por un sentido de pertenencia más elaborado, producto de la exploración sobre la propia cultura, generando una evaluación y reflexión profunda del significado de ser integrante de su cultura, que además genera sentimientos positivos y seguridad desde y hacia el grupo étnico.

Considerando lo anterior, el proceso de desarrollo de la identidad étnica en la adolescencia es dinámico y complejo, implica una relación concreta y experiencial de la persona con su entorno social y cultural, que genera sentimientos de pertenencia, lo que provoca cambios personales y relacionales, que afectan la esfera conductual, el campo cognitivo y el afectivo.

En concordancia con lo anterior, la evidencia empírica ha mostrado que la identidad étnica no es estática, está sometida a modificaciones en la medida en que transcurre el tiempo (Hallett et al., 2008). Al ser socialmente construida, puede cambiar de acuerdo al contexto, variando según momentos y situaciones que ocurren durante la vida (Stephan, 1991 citado en Hallet et al., 2008), así como también según el lazo que se establezca entre el grupo de referencia y su relación con otros grupos.

Un estudio longitudinal (Hallet et al., 2008) mostró que adolecentes indígenas canadienses se identificaron en un primer momento como indígenas, pero en una segunda medición, cerca del $50 \%$ no se identificaron consistentemente como tales, además, existía una diferencia en la autoidentificación según que los sujetos pertenecieran a una reserva aborigen o no. Específicamente, los investigadores reportan que casi la totalidad de estudiantes que viven en una reserva no cambiaron su identificación étnica y el $68 \%$ de la muestra que vivía fuera de las reservas modificó su patrón de autoidentificación. Considerando esto, según los estudiosos, en adolescentes aborígenes la identidad es variable en el tiempo y el estar rodeados por personas de la misma cultura se asocia a un menor cambio en la autoidentificación, al contrario, que si se está inserto en una cultura distinta.

\section{Identidad étnica como factor protector/riesgo en adolescentes}

Diversos estudios han mostrado las relaciones entre la identificación con el grupo de origen con la presencia de conductas antisociales. Se ha observado que, en Estados Unidos, en adolescentes pertenecientes a grupos étnicos con un estado de la identidad del yo establecido, tienen un sentido más positivo de la identidad étnica y se asocia con mayor bienestar psicosocial (Saint Louis \& Liem, 2005).

A partir de la perspectiva de riesgo y resiliencia, un estudio examinó el grado en que la autoestima, la identidad étnica y las orientaciones culturales mediaban o moderaban la relación entre la discriminación percibida y los síntomas depresivos, en adolescentes latinos. Los resultados indicaron que el aumento en los niveles de exploración de la identidad étnica y la resolución positiva de la identidad predijeron mayores niveles de autoestima de los adolescentes (Umaña-Taylor \& Updegraff, 2007).

Brook y Phal (2005) examinaron el potencial protector de la identidad étnica hacia el uso de drogas en una población afroamericana de adolescentes, en Estados Unidos. Los resultados arrojaron que las variables de identidad étnica explicaban el $7 \%$ de la varianza del consumo de droga y estaban inversamente relacionadas con este, así como también aspectos de la identidad étnica atenuaron los factores de riesgo y aumentaron los protectores. Por otra parte, un estudio muestra que los adolescentes que se identifican más fuertemente con su cultura de origen poseen mayor autoestima (Martínez \& Dukes, 1997; Phinney, Cantu, \& Kurtz, 1997).

Así mismo, en adolescentes de culturas minoritarias se ha identificado que un fuerte sentido de identidad étnica, sumado a un sentido de identidad personal consistente, funcionan como elementos protectores ante la presencia de problemas conductuales (Yasui, Dorham, \& Dishion, 2004), conductas sexuales riesgosas 
(Belgrave, Marin, \& Chambers, 2000) y abuso de sustancias (Marsiglia, Kulis, Hecht, \& Sills, 2004).

Por otra parte, otro estudio analizó en población de adolescentes filipinos que residen en Hawái, las relaciones entre la conducta delictiva con la baja identificación cultural y soporte familiar disminuido, los cuales se consideran factores de riesgo importantes hacia la delincuencia. Los resultados arrojaron que la conducta delictiva correlacionó positivamente con estrés aculturativo, con una baja identificación con su grupo étnico e influencia negativa de sus pares. Finalmente, se pudo determinar que las variables más importantes son la influencia de pares y padres ausentes, comparados con una baja identificación étnica, baja autoestima y religiosidad disminuida. Los autores concluyen que no solo importa vincular culturalmente a los adolescentes, sino que esto se acompañe de una vinculación con sus familias y la disminución de la influencia de los pares (Guerrero et al., 2010).

La literatura también indica que la relación entre la identificación con el propio grupo étnico y conductas desadaptativas puede estar influenciada por variables mediadoras. Un estudio encontró que la autoestima mediaba moderadamente la relación entre baja identificación étnica en adolescentes que presentaban conductas antisociales (Schwartz et al., 2007). En el mismo sentido, se ha observado que un mayor sentido de identidad étnica se relacionaba con mayores niveles de autoestima, la cual a su vez se correspondía con menos conductas problema (Wissinka et al., 2008).

La literatura muestra que los adolescentes que mantienen vínculos identitarios con la cultura de origen y la foránea (biculturalismo) presentan un mejor ajuste conductual en comparación a los que no se identifican con estas por sí solas o ambas (DeBerry, Scarr, \& Weinberg, 1996; Phinney \& Devich-Navarro, 1997 citados en Steinberg \& Sheffield, 2001). Finalmente, se ha observado que la presencia de factores asociados a la enculturación, tales como participar en actividades culturales y mantener una mayor autoeficacia funcionan como protectores en contra de problemas mentales en adolescentes indígenas (Bals, Turi, Skre, \& Kvernmo, 2011).

En definitiva, estos estudios, en conjunto, indican que en adolescentes de diversos orígenes étnicos la identificación con su propio grupo étnico se asocia con el aumento del bienestar psicosocial, es decir una mejor calidad de las relaciones que establece con su entorno, favoreciendo el desarrollo sano de su personalidad, además de prevenir la aparición de conductas problema. Así también un bajo nivel de identificación con la cultura de origen se asocia a conductas antisociales y problemas psicológicos.

Sin embargo, la evidencia de esta relación no ha sido estudiada en profundidad en grupos de adolescentes que han cometido delito y que por ende presentan una alta vulnerabilidad psicosocial, ya que se encuentran expuestos a contextos de riesgo delictivo tanto a nivel comunitario, familiar y personal, afectando la calidad relacional y desarrollo psicológico del adolescente.

Identidad étnica en adolescentes infractores
indígenas

A pesar de existir escasa literatura que analice variables de identificación étnica en adolescentes indígenas infractores de ley, los investigadores consideran importante poder profundizar en esta dimensión. Rugge (2006), en un artículo sobre la evaluación del riesgo en infractores indígenas, argumenta que a pesar de existir cierto consenso sobre la existencia de factores protectores y de riesgo que son similares entre adolescentes infractores indígenas y no indígenas, es necesario considerar otros específicos, de los cuales las variables culturales relacionadas con la identidad étnica y la necesidad de pertenencia cultural de los adolescentes dentro de su propia población de infractores son de los más importantes.

Un estudio realizado en Nueva Zelanda, con el objetivo de dar cuenta de los factores de riesgo y protección específicos de la infracción de ley en indígenas Maorí, identificó como variables primordiales el desarrollo de la identidad 
étnica de los infractores, en conjunto con la presencia de conflictos interculturales, además de considerar diferencias en la relación sostenida además de considerar diferencia en el modo de relacionarse con la familia extensa (Whãnau) y los tipos de relación que se mantienen con ésta (Whakawhãnaunga) (Maynard, Coebergh, Anstiss, Bakker, \& Huriwai, 1999). Por otra parte, los mismos autores han argumentado que la existencia de una identidad étnica segura, puede ayudar al cambio hacia conductas positivas entre los infractores Maorí, mostrando además que la identidad étnica confusa pudiera conllevar al surgimiento de emociones negativas tales como el enojo, imágenes negativas de sí mismo, sentimientos depresivos, entre otros.

Desde otro ángulo, para analizar los factores determinantes de la reinserción en una muestra de exinfractores aborígenes Maorí adultos, en un estudio se les consultó sobre aspectos de su reintegración dentro de la sociedad después de salir de la cárcel. Los resultados arrojaron que, de todos los relatos, un $94 \%$ de los sujetos respondió que aprender sobre los valores personales y de su identidad étnica fue primordial para lograr la reinserción (Heckbert \& Turkington, 2001).

En conjunto, estas investigaciones apuntan a que en adolescentes pertenecientes a diversos pueblos indígenas, el grado de identificación con la propia cultura se relaciona con una acentuación o disminución de problemas conductuales, así como también la presencia de conductas antisociales en adolescentes indígenas infractores de ley. Es más, se ha observado cualitativamente, que infractores que ya han cumplido condena señalan importante para el desarrollo personal y el cambio conductual reconocer y participar en la propia cultura de origen, indicando que esta relación tiende a ser inversa: en cuanto mayor desarrollo de la identidad étnica menores conductas antisociales y delictivas.

Actualmente, hay adolescentes mapuche sancionados por la Ley de Responsabilidad Penal Adolescente en Chile, sin embargo, no se sabe con exactitud cuál es su nivel de desarrollo de identidad étnica ni la relación que esta tiene con su conducta. A partir de lo anterior, es necesario analizar el desarrollo de la identidad étnica como un factor de riesgo o bien de protección, hacia el surgimiento o mantención de la conducta antisocial, en especial en adolescentes mapuche que presentan una alta vulnerabilidad social, convirtiéndose así en un foco de análisis importante.

Considerando que el estudio de los factores de riesgo y protectores de la conducta desadaptativa en adolescentes infractores de ley se focaliza principalmente en variables psicosociales comunes con la población general, estas diferencias culturales se estarían invisibilizando entre personas provenientes $\mathrm{y}$ partícipes de distintas culturas y pueblos.

Por otra parte, si bien se han estudiado las relaciones entre la identificación con el grupo étnico de origen en adolescentes, existen escasas investigaciones que se focalicen en asociar específicamente el desarrollo de la identidad étnica con estas conductas en la población adolescente perteneciente a pueblos indígenas.

A partir de lo anterior, el objetivo general de la presente investigación es analizar el grado de vinculación que existe entre el desarrollo de la identidad étnica en adolescentes mapuche que han infringido la ley en Chile con la presencia de conductas sociales. Como objetivo específico, se analizará la relación que existe entre las conductas prosociales y antisociales con las dimensiones de la identidad étnica de Afirmación y Exploración en los adolescentes mapuche infractores de ley. Por otra parte, se analiza si hay diferencias en el grado de desarrollo de la identidad étnica entre adolescentes mapuche infractores de ley y adolescentes estudiantes que no presentan conductas delictivas.

Así mismo, como objetivo específico se estudian las diferencias en las conductas sociales y delictivas entre los adolescentes infractores de ley identificados como mapuche y no mapuche. Como hipótesis se plantea que a un mayor grado de identificación étnica se asocia una menor presencia de conductas antisociales y una mayor presencia de conductas prosociales, así mismo, se espera que a menor grado de desarrollo de la identidad étnica, exista mayor presencia de 
conductas antisociales y menor presencia de conductas prosociales.

\section{Método}

\section{Participantes}

De una población total de 345 adolescentes sancionados en programas dependientes de la red SENAME de las regiones de la Araucanía y Los Ríos en el sur de Chile, partícipes del proyecto FONDEF D08i-1205, se obtuvo una muestra intencionada de 60 adolescentes mapuche. La muestra de adolescentes ingresados a programas de sanción fue seleccionada atendiendo a cuatro criterios: (a) que pertenecieran a las regiones de estudio durante el año 2011; (b) que tuvieran edades entre 14 y 18 años; (c) que fueran autoidentificados como mapuche y (d) que hayan manifestado su consentimiento para participar del estudio.

De una población total de 195 adolescentes asistentes a liceos municipales (públicos) de enseñanza secundaria pertenecientes a la comuna de Ercilla, de la región de la Araucanía, se obtuvo una muestra intencionada de 115, atendiendo a los criterios de: (a) autoidentificación étnica, mediante las preguntas “iEres tú Mapuche?”, “iTe sientes Mapuche?”; (b) con edades entre 14 y 18 años y (c) que hayan manifestado su consentimiento para participar en el estudio. Se elige la comuna de Ercilla porque presenta, de acuerdo a estadísticas oficiales, una de las tasas más altas de población mapuche rural de la Región de La Araucanía, eligiéndose tres establecimientos educacionales con alta prevalencia de estudiantes rurales, pero con diferente composición: uno mayoritariamente mapuche, uno mixto y uno mayoritariamente no mapuche.

\section{Diseño}

Se utilizó un diseño transversal cuantitativo para establecer relaciones entre los niveles de las variables identidad étnica y conducta antisocial y prosocial, variables que se describirán a continuación junto con los instrumentos utilizados para la presente investigación.

Se empleó la prueba no paramétrica de correlación de Pearson; además, comparaciones t de Student para analizar las diferencias de grupo entre los identificados como mapuche y los no mapuche en las variables antes mencionadas. La decisión de utilizar este diseño se debe a que no es objetivo encontrar causalidad entre las variables, sino la asociación entre ellas y la comparación entre los grupos, ya que, al existir escasa evidencia empírica previa, no es posible proponer una hipótesis de causalidad si no existe un análisis que establezca anticipadamente las relaciones entre las variables, siendo este el objetivo metodológico de la presente investigación.

\section{Instrumentos}

\section{Escala de Identidad Étnica Multigrupo (EIEM)}

Actualmente, en Chile no existe la adaptación de este instrumento, ni tampoco para el grupo cultural de adolescentes mapuche, por lo que para su utilización en este trabajo se revisaron las propiedades psicométricas obtenidas de investigaciones internacionales que lo emplearon en grupos hispanoparlantes, angloparlantes y con diversos orígenes étnicos. Diversos estudios dan cuenta de su estabilidad psicométrica de forma consistente, por tanto, la decisión de aplicarlo se debió a la necesidad empírica y la ausencia de investigaciones que pudieran evaluar la relación del desarrollo identitario como factor protector ante conductas antisociales en adolescentes, cuyos resultados pudieran impactar, en un segundo nivel, las estrategias de intervención con este grupo de adolescente.

Un instrumento que mide el desarrollo identitario étnico de adolescentes es la Escala de Identidad Étnica Multigrupo (Phinney, 1992), adaptada al español por Esteban (2010), instrumento que actualmente se considera como una medida general del desarrollo de la identidad étnica. Esta escala además recoge las dimensiones de Exploración y Afirmación 
como aspectos centrales del desarrollo étnico identitario (Phinney \& Ong, 2007).

El instrumento consiste en un cuestionario de autorreporte compuesto por 12 aseveraciones, valoradas en una escala tipo Likert (desde muy en desacuerdo a muy de acuerdo), recogiendo los sentimientos de pertenencia hacia el grupo (la cual tiene 5 ítems), conformando la dimensión de Afirmación y el grado de conocimiento y participación en prácticas culturales (medido mediante 7 ítems), las que conforman la dimensión de Exploración. Este instrumento ha mostrado propiedades psicométricas adecuadas, específicamente se ha confirmado su estructura bifactorial en diversos grupos étnicos de Estados Unidos (Phinney, 1992), Australia (Dandy, Durkin, \& McEvoy, 2007), afroamericanos (Pegg \& Plybon, 2005), americanos latinos y europeos africanos (French, Seidman, Allen, \& Aber, 2006). Así mismo, se ha observado una fuerte correlación entre los constructos de Exploración y Afirmación (Roberts et al., 1999). Al traducirla al español, Esteban (2010) observó que en población hispanoparlante arrojó una buena consistencia interna de la escala global y sus factores en grupos mestizo e indígena.

\section{Cuestionario de Autorreporte de Comportamiento} Social en Adolescentes (CACSA)

Validado en Chile para evaluar las conductas antisociales, tanto en población de adolescentes infractores de ley y no infractores (Alarcón et al., 2010), consiste en una escala autoaplicada que evalúa tres áreas principales de la conducta social: Comportamiento prosocial, comportamiento antisocial total y víctima de abuso de poder. A su vez, la dimensión del comportamiento antisocial se compone de seis subescalas: (a) Delitos, (b) Transgresión contra la Propiedad, (c) Transgresión contra las Personas, (d) Comportamiento Abusivo con Pares y (e) Consumo de Alcohol y Drogas. Los análisis de la validación en una muestra chilena arrojaron que en su conjunto el instrumento muestra buena confiabilidad interna y estabilidad, además de presentar validez interna (convergente) y externa (discriminante). Por otra parte, se observó que entre comportamiento antisocial y prosocial existe una correlación inversa y significativa, lo que indica que toda vez que se observe mayor comportamiento antisocia menor será el comportamiento prosocial, y viceversa (Alarcón et al., 2010).

\section{Escala de Delincuencia Autorrevelada (EDA)}

Consiste en una pauta de entrevista semiestructurada que permite conocer conductas delictivas que han presentado los adolescentes, observadas a través de 63 ítems asociados a distintos delitos agrupados en tres categorías: (a) hurtos y robos, (b) agresiones y (c) otros delitos. Estos ítems se puntúan situando cronológicamente su ocurrencia según siete rangos de edad e indicando la cantidad de veces que ha ocurrido la conducta. Finalmente, contiene un listado de 26 descriptores autorreferenciales y heterorreferenciales que definen el rol dentro del contexto delictivo (Pérez-Luco et al., 2011).

A nivel estadístico este instrumento muestra índices de consistencia interna adecuados $(\alpha$ $=0.95)$ para delitos de hurto y robos; para agresiones $(\alpha=0.8)$ y para otros delitos $(\alpha=0.61)$. Se ha señalado que este instrumento es valorado por identificar patrones delictivos persistentes, indicando especialización y polimorfismo de las conductas delictivas y permitiendo explorar la conformación de trayectorias delictivas en adolescentes (PérezLuco et al., 2012).

\section{Ficha de Evaluación de Riesgos y Recursos (FER- R)}

Instrumento de juicio profesional estructurado y construido en Chile (Alarcón, 2001). Usa registro dicotómico (presencia/ausencia) para estimar un índice de valoración de riesgo global. Está compuesto por 51 ítems distribuidos en siete factores, además de un índice global de recursos para la intervención, compuesto por dos factores con 17 ítems en total. Estadísticamente, las 
dos escalas presentan una elevada consistencia interna para Riesgo Global $(\alpha=0.94)$ y para Recursos Protectores $(\alpha=0.81)$ y también para cada uno de los nueve factores $(\alpha=$ entre 0.64 y 0.88).

\section{Procedimiento}

La población total de adolescentes fue evaluada mediante el Protocolo de Evaluación Diferenciada del Proyecto FONDEF D08i-1205, que incluye un total de 14 instrumentos de autorreporte de delitos, comportamientos sociales, identidad étnica, valoración de riesgos y recursos personales, familiares y comunitarios, entre otros. Para identificar a los adolescentes pertenecientes al pueblo mapuche dentro de este protocolo, se utilizó el criterio de autoidentificación étnica a partir de las preguntas “¿Eres tú mapuche?” y “iTe sientes mapuche?”, y se recogió además el juicio de identificación étnica de los profesionales responsables de la intervención.

Paralelamente, se utilizó el criterio de autoidentificación étnica a partir de las preguntas "¿Eres tú mapuche?" y "iTe sientes mapuche?" en la muestra de adolescentes estudiantes de enseñanza secundaria de la comuna de Ercilla. La decisión de emplear estos dos criterios de autoidentificación tiene por objetivo conocer de forma exploratoria, si una pregunta de pertenencia étnica que tiene un componente afectivo, genera diferencias en comparación con una pregunta que, si bien orienta a la persona hacia una autobservación de identificación hacia un grupo étnico, estaría determinada por el contexto de referencia y/o la presencia de un apellido mapuche en la persona.

Por otra parte, en la muestra de estudiantes, se aplicó la Escala de Identidad Multigrupo, con el objetivo de conocer el grado de desarrollo de la identidad étnica de estos adolescentes, lo cual permitió realizar análisis comparativos en el grado de desarrollo de la identidad étnica entre el grupo de adolescentes infractores y el grupo de estudiantes. Una vez obtenida la información, se construyó una base de datos donde se registraron las respuestas de los adolescentes para su análisis estadístico.

Análisis de datos

Para el tratamiento de los datos, se realizaron tres tipos de análisis. Mediante análisis descriptivos, respecto a los criterios de autoidentificación hacia el pueblo mapuche, tanto del grupo de adolescentes estudiantes como los infractores, se obtuvo la descripción de la frecuencia y porcentajes según la autoidentificación étnica y juicio profesional. Posteriormente, se llevaron a cabo comparaciones de grupo, mediante la prueba $t$ de Student, para analizar las diferencias entre los adolescentes estudiantes mapuche e infractores mapuche respecto a la autoidentificación étnica. Así mismo, se realizaron comparaciones de grupo, mediante la prueba $t$ de Student, para contrastar los grupos de infractores no mapuche y mapuche, a razón de los delitos tanto judicializados como no judicializados. Asimismo, se hicieron comparaciones de grupo, entre adolescentes infractores de ley autoidentificados como no mapuche y adolescentes autoidentificados como mapuche, respecto a las conductas sociales. Posteriormente, se hicieron análisis correlacionales entre las variables de identidad étnica y conductas sociales, dentro del grupo de los adolescentes infractores autoidentificados como mapuche.

\section{Resguardos éticos}

Debido a que la muestra se compone de adolescentes menores de edad sancionados por la ley de responsabilidad penal adolescente, se resguardó el derecho a la voluntariedad de la participación en el estudio, además de la completa confidencialidad de la identidad de los participantes de esta investigación. Para lo anterior, a cada adolescente se le comunicó, mediante un consentimiento informado, respecto a los motivos de la investigación y la confidencialidad de la información obtenida, protocolo que fue firmado 
por el adolescente y el encargado de realizar recolección de los datos. Además, dado que se obtuvo información sobre aspectos identitarios relacionados con la cultura de origen, era posible que en los adolescentes existieran inquietudes que debían ser abordadas después de la aplicación de las pruebas, por lo cual se estableció el compromiso de responder a las interrogantes y de facilitar toda la información necesaria para satisfacer las demandas de los jóvenes, aspecto que también está descrito dentro del consentimiento informado que los adolescentes firmaron.

\section{Resultados}

\section{Criterio de selección por autoidentificación}

Adolescentes infractores de ley identificados como mapuche

Los análisis descriptivos indicaron que el $17.4 \%$ de los adolescentes contestaron afirmativamente a la pregunta "iEres tú mapuche?". Por otra parte, se les consultó a los adolescentes " iTe sientes mapuche?", observando que del total de la muestra el $15.1 \%$ de ellos se sienten mapuche. Así mismo, mediante criterio profesional se observó que del total de adolescentes de la muestra, el $11.9 \%$ fueron identificados como mapuche, sin embargo, existen datos perdidos (61 casos) al analizar este criterio (18.3\%) por lo que en adelante se utilizaron solo los criterios autodescriptores para los análisis. Considerando solo los criterios de autoidentificación, se analizó si existía independencia entre ambos mediante la prueba de chi-cuadrado. Los resultados muestran que los criterios presentan una alta correlación $(\chi=0.725)$ en la muestra de adolescentes infractores autoidentificados como mapuche, siendo esta significativa $(p<0)$.
Adolescentes estudiantes identificados como mapuche

Por otra parte, del total de 195 adolescentes de la muestra de estudiantes, se observó que el 59 \% respondió afirmativamente a la pregunta “iEres tú mapuche?”. Ante la pregunta “¿Te sientes mapuche?", el 54.5 \% respondió afirmativamente. Asimismo, considerando ambos criterios de autoidentificación, se analizó si existía independencia entre ellos mediante la prueba de chi-cuadrado. Los resultados indicaron que estos criterios presentan una alta correlación $(\chi=0.772)$ siendo además significativa $(p<0)$.

\section{Figura 1}

Respuesta de los adolescentes a criterios de identificación mapuche en muestra infractores y estudiantes

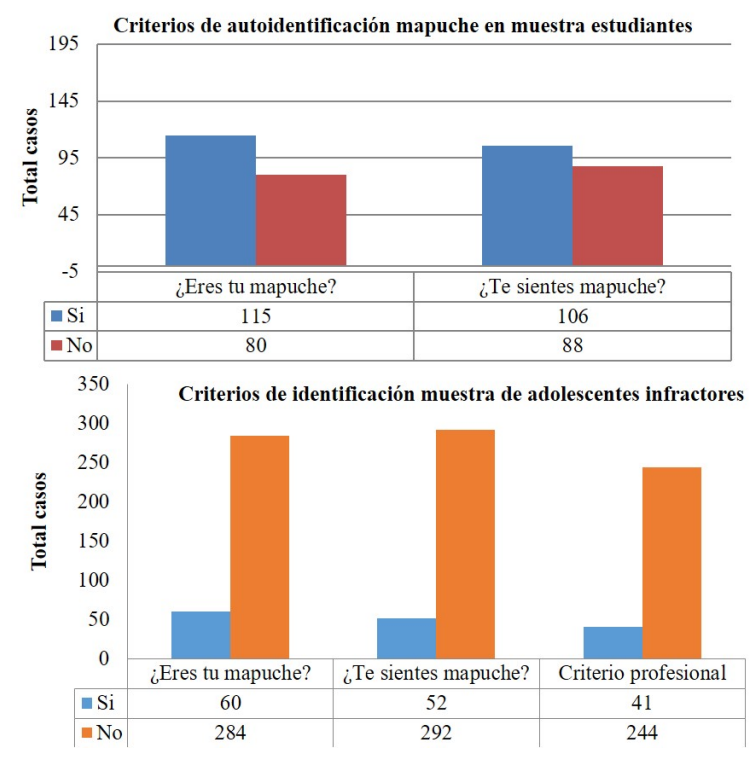

Fuente: elaboración propia

Por otra parte, se observa una menor proporción de autoidentificados como mapuche en la muestra de infractores que en la muestra de estudiantes. 


\section{Figura 2}

Proporción porcentual de adolescentes autoidentificados mapuche en muestras de infractores y estudiantes

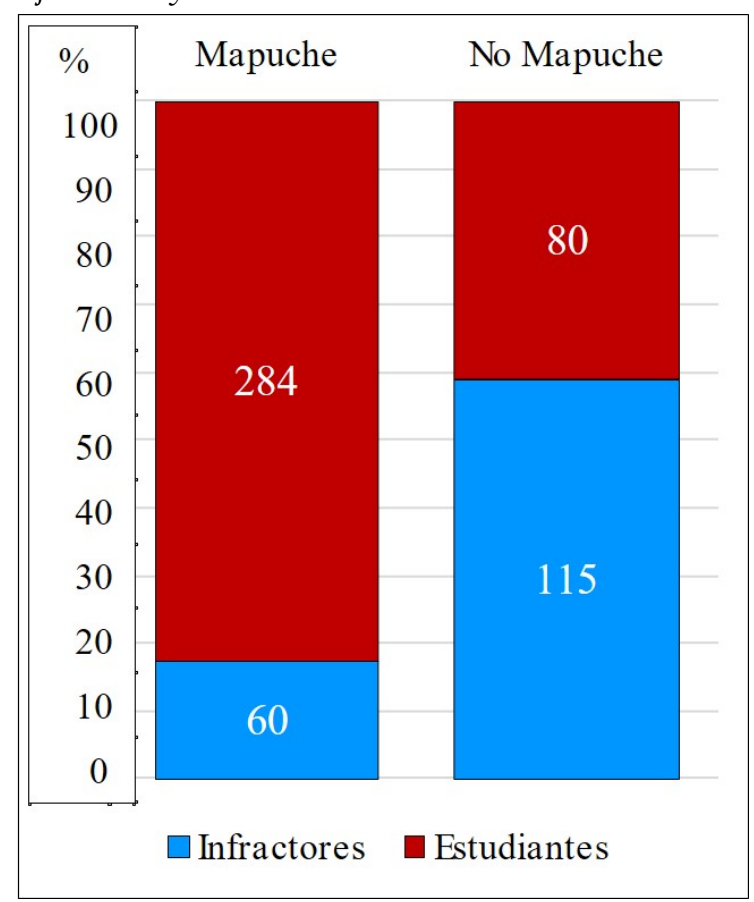

Fuente: elaboración propia

Comparaciones de grupo entre muestras de adolescentes estudiantes mapuche e infractores mapuche y no mapuche

Identidad étnica entre adolescentes mapuche infractores y estudiantes mapuche

Para analizar la asociación entre la Identidad Étnica Total y las dimensiones Exploración y Afirmación en ambos grupos, se realizó un análisis de correlación de Pearson, donde se observó que existe una alta correlación $(\underline{r}=$ 0.971) entre la dimensión Afirmación con la Identidad étnica total $(p<0)$, así como también una alta correlación $(\underline{r}=0.929)$ entre la dimensión Exploración con la Identidad étnica total $(p<0)$.

Con el objetivo de analizar la relación entre las dimensiones de Afirmación y Exploración, se llevó a cabo también un análisis de correlación de Pearson, donde los resultados muestran que existe una alta correlación $(\underline{r}=0.814)$ entre las dimensiones de Afirmación y Exploración de forma significativa $(p<0)$. Ambos resultados confirman las investigaciones internacionales señaladas anteriormente que indican la alta correlación entre ambas dimensiones, como la relación de ambas con la escala total encontrada en diferentes grupos étnicos en el mundo, mostrando que el instrumento se comporta de forma similar en el grupo de adolescentes mapuche.

Para analizar si existen diferencias en el desarrollo de la identidad étnica entre el grupo de adolescentes mapuche infractores de ley y adolescentes estudiantes mapuche, se realizó una prueba $t$ para comparar las medias de ambos grupos en el desarrollo de la identidad étnica total y de las dimensiones de Afirmación y Exploración. Los análisis indican que no existen diferencias $(t=0.133)$ de promedio significativas $(p>0.894)$ respecto a la identidad étnica total entre los adolescentes mapuche infractores y adolescentes estudiantes mapuche. Así mismo, no existen diferencias $(t=0.511)$ significativas en los promedios de la dimensión de Afirmación $(p>0.611)$. Por otra parte, tampoco aparecen diferencias significativas ( $t$ $=-1.05$ ) en la dimensión Exploración ( $p>$ 0.296). Finalmente, considerando que en ambos grupos se obtuvieron medias similares en los puntajes de la Escala de Identidad Étnica, cualitativamente, se observa una leve tendencia a mostrar una mayor afirmación hacia la cultura que la exploración hacia esta. 


\section{Figura 3}

Promedio comparado entre mapuche estudiantes e infractores en la escala de Identidad Étnica

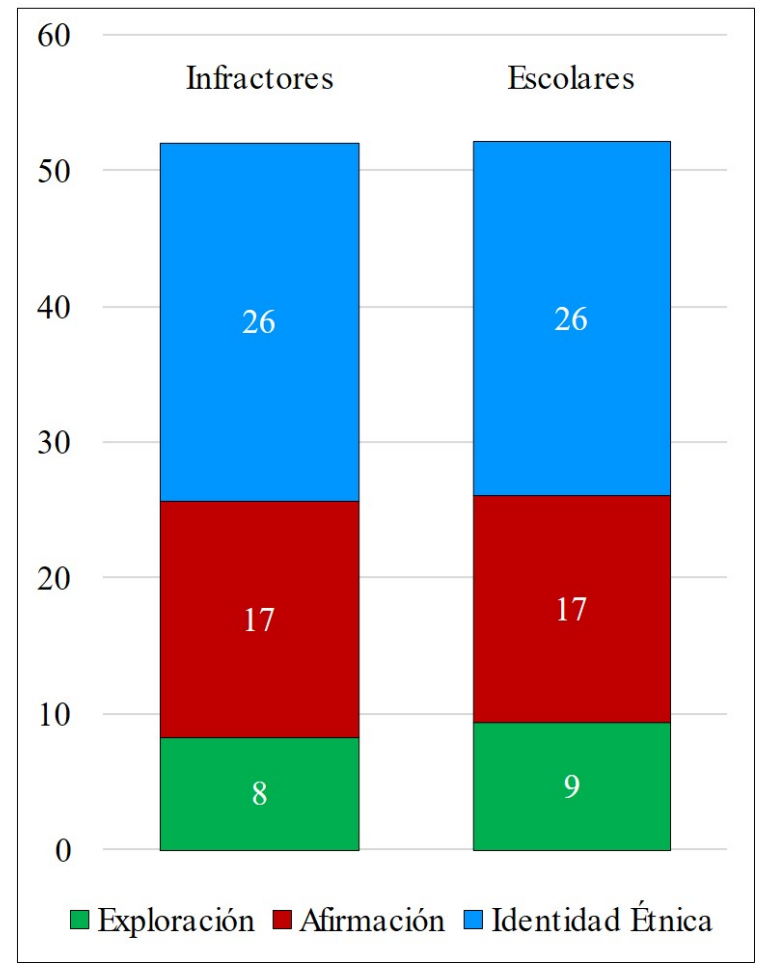

Fuente: elaboración propia

Infractores no mapuche y mapuche en delitos judicializados y delitos autorreportados

Para evaluar diferencias en la cantidad de delitos cometidos entre adolescentes infractores no mapuche y mapuche se realizó una prueba de diferencias de promedio mediante la prueba t. Los resultados indican que entre ambos grupos no existen diferencias de promedio $(t=-0.542)$ significativas $(p>0.588)$ en la cantidad de delitos judicializados.

Para observar si existen diferencias en la cantidad de delitos autorreportados entre el grupo de infractores no mapuche y mapuche, se realizó una prueba de diferencia de promedio mediante la prueba $t$. Los resultados indican diferencias significativas $(p<0.001)$ entre el promedio total de la cantidad de delitos autorreportados entre los infractores no mapuche $(\mathrm{m}=356)$ y los infractores autoidentificados como mapuche $(\mathrm{m}=96)$. Respecto a los delitos más frecuentemente autorreportados, se observa cualitativamente que en promedio ambos muestran más delitos de hurto (no mapuche $\mathrm{m}=293$; mapuche $\mathrm{m}=74$ ), sin embargo, no existen diferencias significativas entre ambos grupos respecto a los delitos específicos, tales como delitos contra la propiedad $(t=2.941$; $p>0.186)$, delitos contra las personas $(t=$ $0.969 ; p>0.334)$ y otros delitos $(t=1.141$; $p>0.255)$. Lo anterior indica que si bien ambos grupos poseen similar cantidad de delitos judicializados, aquellos autorreportados por los propios adolescentes son significativamente distintos, observándose que, a pesar de poseer menor cantidad de delitos autorreportados, los adolescentes mapuche son igualmente sancionados que los no mapuche, que poseen mayor cantidad de delitos autorreportados. Lo anterior conllevaría a un análisis más exhaustivo y planteamiento de hipótesis que respondan a estas diferencias en ambos grupos.

\section{Figura 4}

Diferencias de promedio entre adolescentes infractores mapuche y no mapuche en delitos judicializados y autorreportados

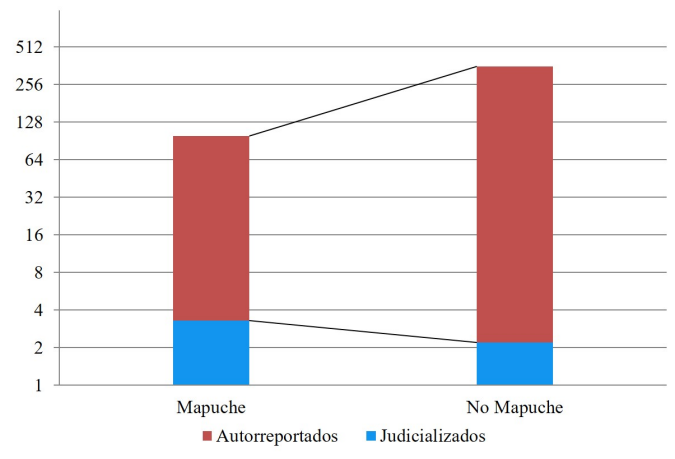

Fuente: elaboración propia

Conductas sociales entre adolescentes infractores mapuche y no mapuche

Para comparar si existen diferencias entre el comportamiento social entre los adolescentes infractores de ley identificados como mapuche y los no mapuche, se empleó una prueba $t$ para comparar las medias de ambos grupos, tanto 
para las conductas antisociales y prosociales, mediante el instrumento CACSA. Los análisis arrojan que no existen diferencias de promedio $(t$ $=-0.098)$ significativas $(p>0.929)$ en las medias de los puntajes de las conductas prosociales entre el grupo mapuche y no mapuche. Al comparar las conductas antisociales entre ambos grupos, no se observan diferencias de promedio $(t=0.129)$ significativas $(p>0.898)$ entre los adolescentes mapuche y no mapuche. Lo anterior indica que en comparación en ambos grupos existe un balance entre conductas sociales y antisociales, dato que se contrapone con las diferencias en los delitos autorreportados entre ambos. Esto se asocia con que las conductas antisociales analizadas mediante el instrumento CACSA engloban no solo conductas delictivas, sino aquellas contra las normativas en general, pero que, al focalizarse en las primeras, las diferencias de grupo son importantes, dando cuenta de que el aspecto diferenciador entre ambos grupos son las conductas delictivas en específico y no las conductas antisociales en general.

\section{Figura 5}

Diferencias en conductas prosociales y antisociales (CACSA) entre adolescentes infractores mapuche y no mapuche

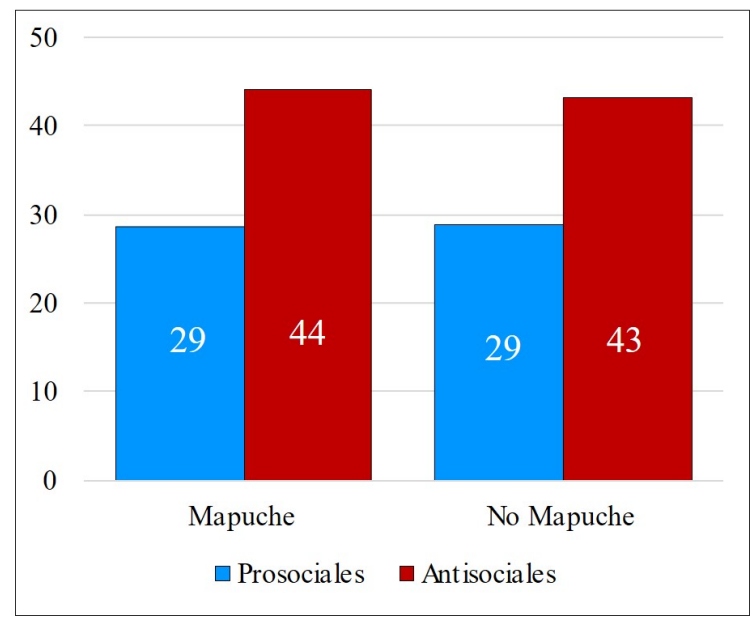

Fuente: elaboración propia
Asociación entre identidad étnica y conductas sociales en adolescentes infractores autoidentificados como mapuche

Respecto al objetivo general de establecer relaciones entre la identidad étnica y las conductas sociales en los adolescentes infractores de ley autoidentificados como mapuche, se realizó un análisis de correlación de Pearson, cuyos resultados arrojaron la existencia de una relación inversa baja entre la identidad étnica y comportamientos antisociales de forma significativa. Específicamente, existe una asociación inversa entre mayor desarrollo de la identidad étnica con menor presencia de conductas antisociales. A su vez, no se observaron relaciones significativas entre la identidad étnica y el comportamiento prosocial. Por otra parte, con el objetivo de analizar las relaciones entre las dimensiones de Exploración y Afirmación con las conductas prosociales y antisociales se realizó análisis de correlaciones de Pearson, cuyos los resultados indican la existencia de una relación inversa baja entre conductas antisociales y la dimensión de Exploración, siendo esta significativa. Respecto a la relación entre la dimensión de Afirmación y conductas antisociales, se observó una discreta relación inversa, siendo esta significativa. Por otra parte, no se apreciaron relaciones significativas entre las conductas prosociales con las dimensiones de Afirmación y Exploración (Tabla 1).

\section{TABLA 1}

Matriz de correlaciones entre la identidad étnica total, sus dimensiones de Afirmación y Exploración del IEM con las conductas prosociales y antisociales del CACSA

\begin{tabular}{llllc}
\hline & \multirow{2}{*}{ Exploración } & \multirow{2}{*}{ Afirmación } & $\begin{array}{l}\text { Conducta } \\
\text { Prosocial }\end{array}$ & $\begin{array}{c}\text { Conducta } \\
\text { Antisocial }\end{array}$ \\
\hline \multirow{2}{*}{ IEM } & 0.93 & 0.979 & 0.121 & -0.2 \\
& 0 & 0 & 0.094 & 0.006 \\
Exploración & & 0.835 & 0.115 & -0.226 \\
& & 0 & 0.107 & 0.002 \\
Afirmación & & & 0.113 & -0.181 \\
& & & 0.119 & 0.014 \\
\hline
\end{tabular}

Fuente: elaboración propia 


\section{Discusión}

El objetivo de la presente investigación fue analizar la relación entre las conductas sociales y la identidad étnica en adolescentes indígenas mapuche que han infringido la ley, lo anterior con el fin de evaluar empíricamente si la identidad étnica pudiera considerarse como un factor protector asociado a la conducta antisocial en este grupo de adolescentes.

Los primeros resultados muestran que el grado de desarrollo de la identidad étnica entre adolescentes mapuche estudiantes e infractores de ley es similar. Así mismo, en ambos se observó un nivel medio de desarrollo de la identidad étnica, lo que a la luz del modelo planteado por Phinney (1989) significa que ambos grupos se encontrarían en un estado de la identidad situado entre la delegación y la moratoria, indicando que en la primera, los adolescentes se identifican afectivamente con la propia cultura, pero que no han realizado una búsqueda activa para conocer y participar en ella. Esto además pudiera deberse a la escasa posibilidad en el contexto socializador que permita la exploración, el conocimiento y la participación en las prácticas culturales. En la segunda, que participan de ella, pero que afectivamente aún no se han vinculado con su cultura, por lo tanto sin aún valorarla como propia, lo que pudiera deberse a los procesos de estigmatización y discriminación, señalados anteriormente.

Desde otra perspectiva, a pesar de que un 46.5 $\%$ de la población de la comuna de Ercilla, donde residen los adolescentes estudiantes de la muestra de enseñanza secundaria son mapuche, tiene uno de los mayores porcentajes a nivel nacional (Comisión Económica para América Latina y el Caribe [CEPAL], 2012), el grado de desarrollo de la identidad étnica en ambas muestras es en promedio similar. Esto podría indicar que tanto en contextos judicializados como en aquellos territorialmente densos en población mapuche, el bajo grado de desarrollo de la identidad étnica en estos adolescentes pudiera asociarse a procesos de aculturación que impactan de forma transversal a la población adolescente mapuche. Desde una mirada histórica y contextual, lo anterior es consistente con lo que plantea Hart (2002 citado en Holwell, 2008), que menciona que cuando las experiencias de colonización han sido internalizadas por las personas pertenecientes a los pueblos indígenas, estas influyen en todos los ámbitos: emocional, mental y espiritual. Se genera así una percepción de confusión y debilitamiento, ya que se sienten presionados a desvincularse de lo que ellos son, y en la medida en que están más internalizadas, existe una mayor tendencia a dejar de reconocerse como tales, generando la pérdida de su identidad. Por lo tanto, para los adolescentes pertenecientes a los pueblos indígenas, existe un factor que agrega complejidad a la ya crítica tarea de negociar la conformación de la identidad en un contexto interpersonal culturalmente asimétrico, dado que se está enfrentando el estatus de pueblo indígena dentro de la cultura dominante, al mismo tiempo que tener que resolver su identidad étnica, la cual le indica quién es en la sociedad (Umaña-Taylor \& Updegraff, 2007).

Los análisis descriptivos de la población total indicaron que de los 345 adolescentes infractores de ley (un $17.4 \%$ ) se autoidentificó como mapuche, porcentaje menor que aquellos autoidentificados como mapuche de la muestra de estudiantes (40.6\%). Si solo se compararan ambas muestras, se podría concluir preliminarmente que existe una subrepresentación en el sistema judicial de adolescentes pertenecientes al pueblo mapuche. Sin embargo, como se mencionó anteriormente, la comuna de Ercilla, presenta uno de los mayores porcentajes de personas pertenecientes al pueblo mapuche a nivel nacional (CEPAL, 2012), lo que explica las características identitarias de la población de estudiantes secundarios, situación demográfica que no es representativa de la población adolescente mapuche del país.

No obstante, al comparar la muestra de infractores mapuche y la población adolescente identificada como mapuche a nivel país, se observa que aproximadamente un $7 \%$ se identifica con este pueblo (INE, 2009). Desde esta perspectiva, el $17.4 \%$ de adolescentes infractores mapuche implican una sobrerrepresentación de adolescentes mapuche 
en el sistema judicial. Esta sobrerrepresentación sería concordante con lo observado en el sistema penal en otros países, tales como Australia (Allard et al., 2010), Hawái (Hishinuma et al., 2005), Canadá (Rojas \& Gretton, 2007), entre otros. Según estos autores este fenómeno se asocia a procesos de marginalización, pobreza y a las dificultades de los adolescentes por adaptarse a la sociedad dominante, aspectos vinculados al proceso de colonización sufrida desde hace varios siglos.

Considerando estos resultados, e integrándolos con lo observado en las conductas delictivas de los adolescentes en este estudio, las comparaciones entre los grupos de infractores no mapuche y mapuche, respecto a los delitos judicializados y autorreportados, indican que, si bien los judicializados en el grupo de adolescentes no mapuche no difieren del grupo mapuche, la cantidad de delitos autorreportados por estos últimos son significativamente menores, indicando la existencia de trayectorias delictivas menos complejas, a pesar de presentar, en promedio, la misma cantidad de delitos sancionados por el sistema penal.

Al analizar los resultados desde la mirada de los factores de riesgo y protección, estas asimetrías observadas en los delitos judicializados y autorreportados pudieran asociarse a diversos fenómenos. Desde el punto de vista de los adolescentes no mapuche, estas diferencias pudieran explicarse debido a que existen mayores riesgos en diversas áreas asociadas al actuar delictivo, en comparación con el grupo de adolescentes mapuche, específicamente asociado al aprendizaje y desarrollo de mayores habilidades para eludir la detección policial y/o también debido a que el contexto social pudiera normalizar estas conductas, siendo mayormente invisibilizadas.

Desde el punto de vista de los adolescentes mapuche, pudiera asociarse a que tempranamente se involucrarían en conductas delictivas que son más frecuentemente condenables por la ley, pero también que pudieran presentar menores habilidades asociadas al actuar delictivo y por ende son mayormente detectados por el sistema penal y policial, como también pudiera argumentarse que culturalmente existe una menor tolerancia hacia la comisión de delitos y por ende sean detectados más tempranamente. Estas interrogantes deben ser respondidas en próximos estudios donde se analicen los riesgos y recursos comparativamente en ambos grupos de adolescentes infractores, considerando no solo aquellos factores de riesgo que tradicionalmente se han descrito en la literatura asociada a la delincuencia juvenil, sino que también de forma específica, según las diferencias culturales y particularidades de esta población adolescente. De importancia para la presente investigación, y situándose desde una mirada diferenciadora culturalmente, el que se observe una menor cantidad de conductas delictivas autorreportadas en adolescentes mapuche pudiera relacionarse con la presencia de factores protectores a nivel social e individual, que impiden un mayor compromiso delictual, comparados con los adolescentes no mapuche.

A la luz de lo anterior, considerando el objetivo principal de esta investigación, los resultados confirman la existencia de una relación entre desarrollo de la identidad étnica y las conductas sociales en los adolescentes mapuche infractores de ley. Específicamente, se confirma la hipótesis planteada, indicando que un mayor grado de desarrollo de la identidad étnica se asocia con una menor presencia de conductas antisociales. A esto, los resultados también indican que existe una ausencia de relación entre la identidad étnica y una mayor presencia de conductas prosociales.

Estos resultados pueden ser de importancia para la intervención, ya que apuntarían a que un desarrollo balanceado de la identidad étnica (basado en la afirmación de la persona con el grupo, el explorar vivencialmente, conociendo y practicando las costumbres de su cultura, en conjunto) funcionarían como factores protectores respecto de las conductas antisociales, pero sin que necesariamente promueva mayores conductas prosociales.

Por otra parte, que la dimensión de Exploración muestre, cualitativamente, una mayor relación con menores conductas antisociales que la dimensión de Afirmación, 
pudiera indicar que el acto de conocer la propia cultura, en la acción de participar vivencialmente en ella, y no solo el proceso mental de valorarla, se vincularía con una menor presencia de conductas antisociales en estos adolescentes. Lo anterior apunta a la necesidad de una planificación distinta en la forma de implementar acciones preventivas y de disminución de conductas antisociales en adolescentes mapuche infractores de ley. Concretamente, implica que la intervención debiera promover una mayor vinculación de los adolescentes a contextos donde puedan conocer, vivenciar y participar con otros, en un espacio relacional y físico de las costumbres de su propia cultura, más allá de la sola valoración de la propia cultura.

Desde el punto de vista de los factores de riesgo y protección, la literatura revisada indica que a nivel internacional, existen escasas investigaciones que hayan analizado empíricamente la relación entre la identidad étnica con los procesos de desadaptación social adolescente, sin embargo, los resultados son congruentes con aquellas investigaciones que argumentan la importancia de comprender los factores específicos asociados a la disminución de las conductas antisociales en adolescentes pertenecientes a pueblos indígenas, convirtiéndose en el mayor aporte de la presente investigación.

$\mathrm{Al}$ analizar estos resultados, a la luz de los procesos de intervención en la prevención o disminución de las conductas antisociales en adolescentes pertenecientes a pueblos indígenas, se debieran generar intervenciones que se orienten no solo a la distinción de las diferencias culturales, sino, además, a favorecer la participación activa del adolescente en espacios culturales, y así a posibilitar que conozcan, exploren y valoren su propia cultura indígena, potenciando así el crecimiento de su propia identidad.

Considerando los resultados de la investigación, a nivel de políticas públicas es necesario fortalecer la identidad indígena en las acciones de prevención de la infracción de ley adolescente, además de, a nivel de intervención especializada, desarrollar una mirada integral acerca de aquellos adolescentes mapuche que han infringido la ley, lo que incluye la promoción de su identidad étnica. Esta identidad étnica, entonces, es entendida como un factor protector dinámico, es decir, que provoca cambios emocionales, conductuales y relacionales, que co-ocurren con el surgimiento normativo de conductas desadaptadas en la etapa de la adolescencia y no como un predisponente de estas.

A nivel metodológico, dado que el proceso de construcción de la identidad étnica es dinámico y por tanto la relación con las conductas sociales cambia con el tiempo, los resultados muestran parcialmente el vínculo entre la identidad étnica y las conductas sociales en un momento particular, debido a la naturaleza del diseño transversal de la investigación. Por lo tanto, futuras líneas de trabajo en esta temática debieran integrar un diseño longitudinal, que permita analizar los cambios del desarrollo de la identidad étnica en el tiempo, los factores que inciden y las relaciones que surgen, observando los cambios en las conductas sociales, especialmente si los adolescentes están insertos en programas de intervención.

Por último, en este estudio solo se analizó la situación de adolescentes mapuche, requiriéndose más estudios en los casos de adolescentes de otros pueblos indígenas en Chile y en otros países, especialmente donde el proceso de colonización ha generado condiciones de vulnerabilidad tales, que impactan negativamente en el desarrollo y adaptación adolescente.

\section{Agradecimientos}

Este proyecto, planteado desde la investigaciónacción, se propuso trabajar directamente con los interventores de los programas que ejecutan las sanciones, brindándoles la formación especializada requerida para una evaluación diferenciada y la supervisión necesaria para asegurar el logro de la competencia buscada. El proceso se realizó con 48 profesionales de tres instituciones distintas que administran sanciones 
en los diferentes sistemas, desde Santiago a Puerto Montt (centro-sur de Chile), cada uno de los cuales condujo entre 5 y 10 evaluaciones completas a adolescentes, con los que les correspondía intervenir.

\section{Referencias}

Agostini, C., Brown, P., \& Román, A. (2010). Poverty and inequality among ethnic groups in Chile. World Development, 38(7), 1036-1046.

Alarcón, P. (2001). Evaluación psicológica de adolescentes con desadaptación social (Tesis de maestría inédita). Universidad de Salamanca, Salamanca.

Alarcón, P. (2015). Una aproximación multidimensional al comportamiento antisocial durante la adolescencia (Tesis doctoral inédita). Universidad Pontificia de Salamanca, Salamanca.

Alarcón, P., Pérez-Luco, R., Salvo, S., Roa, G., Jaramillo, K., \& Sanhueza, C. (2010). Validación del cuestionario de autoreporte de comportamiento antisocial en adolescentes: CACSA. Paidéia, 20(47), 291-302.

Alarcón, P., Pérez-Luco, R., Wenger, L., Chesta, S., Lagos, L., Salvo, S., ... Berríos, C. (2014). MMIDA. Modelo Multidimensional de Intervención Diferenciada con Adolescentes: Manual de evaluación diferenciada: Evaluar para intervenir. (Vol. 2). Temuco: Ediciones Universidad de La Frontera.

Alarcón, P., Vinet, E., \& Salvo, S. (2005). Estilos de personalidad y desadaptación social durante la adolescencia. Psykhe, 14(1), 3-16.

Allard, T., Stewart, A., Chrzanowski, A., Ogilvie, J., Birks, D., \& Little, S. (2010). The use and impact of police diversion for reducing indigenous overrepresentation. Brisbane, Autralia: Griffith University.

Bals, M., Turi, A., Skre, I., \& Kvernmo, S. (2001). The relationship between internalizing and externalizing symptoms and cultural resilience factors in Indigenous Sami youth from Arctic Norway. International Journal of Circumpolar Health, 70(1). Recuperado de http://ijch.fi/aheadofprint.php

Belgrave, F., Marin, B., \& Chambers, D. (2000). Cultural, contextual, and intrapersonal predictors of risky sexual attitudes among urban African American girls in early adolescence. Cultural Diversity and Ethnic Minority Psychology, 6(3), 309-322.

Brook, J., \& Phal, K. (2005). The protective role of ethnic and racial identity and aspects of an Africentric orientation against drug use among African American young adults. The Journal of Genetic Psychology, 166(3), 329-345. doi: 10.3200/ GNTP.166.3.329-345

Comisión Económica para América Latina y el Caribe \& Alianza Territorial Mapuche. (2012). Desigualdades territoriales y exclusión social del pueblo mapuche en Chile: situación en la comuna de Ercilla desde un enfoque de derechos (Documentos de Proyectos N. ${ }^{\circ}$ 473). Chile: Santiago de Chile. Recuperado de http://www.cepal.org/es/publicaciones/3 974-desigualdades-territoriales-exclusion-s ocial-pueblo-mapuche-chile-situacion-la

Coie, J., Terry, R., Lenox, K., Lochman, J., \& Hyman, C. (1995). Childhood peer rejection and aggression as predictors of stable patterns of adolescent disorder. Development and Psychopathology, 7, 697-713. doi: 10.1017/ S0954579400006799

Correa, M., \& Mella, E. (2010). Las razones del "illkun"/enojo. Memoria, despojo y criminalización en el territorio mapuche de Malleco. Chile: Lom Ediciones/ Observatorio de Derechos de los Pueblos Indígenas.

Dandy, J., Durkin, K., \& McEvoy, P. (2007). Psychometric properties of Multigroup Ethnic Identity Measure (MEIM) scores with Australian adolescents from diverse ethno cultural group. Journal of Adolescence, 31(3), 323-335.

DeBerry, K. M. R. (1996). Family racial socialization and ecological competence: 
Longitudinal assessments of AfricanAmerican transracial adoptees. Child Development, 67, 2375-2399.

Eamon, M., \& Mulder, C. (2005). Predicting antisocial behavior among Latino young adolescents. American Journal of Orthopsychiatry, 75(1), 117-127. doi: 10.1037/0002-9432.75.1.117

Esteban, M. (2010). Propiedades psicométricas y estructura factorial de la Escala de Identidad Étnica Multigrupo en español (MEIM). Revista Latinoamericana de Psicología, 42 (3), 405-412.

Fabio, A., Tu, L.-C., Loëber, R., \& Cohen, J. (2011). Neighborhood socioeconomic disadvantage and the shape of the agecrime curve. American Journal of Public Health, 101(1), 325-332. doi: 10.2105/ AJPH.2010.300034

Farrington, D. P. (1996). The explanation and prevention of youthful offending. En P. Cordelia \& L. Siegel (Eds.), Readings in contemporary criminological theory (pp. 257-272). Boston: Northeastern University Press.

Fréchette, M., y Le Blanc, M. (1998). Délinquances et délinquants (8 $8^{\underline{a}}$ ed.). Québec: Gaêtan Morin.

French, S., Seidman, E., Allen, L., \& Aber, J. (2006). The development of ethnic identity during adolescence. Developmental Psychology, 42(1), 1-10. doi: 10.1037/0012-1649.42.1.1

Guerrero, A., Nishimura, S., Chang, J., Ona, C., Cunanan, V., \& Hishinuma, E. (2010). Low cultural identification, low parental involvement and adverse peer influences as risk factors for delinquent behavior among Filipino youth in Hawai'i. International Journal of Social Psychiatry, 56(4), 371-388.

Hallett, D., Want, S., Chandler, M., Koopman, L., Flores, J., \& Gehrke, E. (2008). Identity in flux: Ethnic self-identification and school attrition in Canadian Aboriginal youth. Journal of Applied Developmental Psychology, 29, 62-75.

Heckbert, D., \& Turkington, D. (2001). Turning points: A study of the factors related to the successful reintegration of Aboriginal offenders (Informe N.o R-61). Otawa: Correctional Services of Canada.

Hishinuma, E. S., Johnson, R., Kim, P., Nishimura, S., Makini, G., Andrade, N., ... Revilla, L. (2005). Prevalence and correlates of misconduct among ethnically diverse adolescents of native Hawaiian/Part-Hawaiian and NonHawaiian ancestry. International Journal of Social Psychiatry, 51 (3), 242-258.

Hoeve, M., Blokland, A., Dubas, J., Loeber, R., Gerris, J. R. M., \& Van der Laan, P. (2008). Trajectories of delinquency and parenting styles. Journal of Abnormal Child Psychology, 36(2), 223-235. doi: 10.1007/ s10802-007-9172-x

Howell, T. (2008). The point of no return: Aboriginal offenders' journey towards a crime free life (Tesis doctoral inédita). University of British Columbia, Canadá.

Instituto Nacional de Estadísticas. (2002). Compendio Estadístico. Santiago: Autor. Recuperado de http://www.ine.cl

Instituto Nacional de Estadísticas. (2009). Compendio Estadístico. Santiago: Autor. Recuperado de http://www.ine.cl

Instituto Nacional de Estadísticas. (2014). Proyecciones de población 2002-2020. Santiago: Autor. Recuperado de http://ww w.ine.cl

Kazdin, A., \& Buela-Casal, G. (2002). Conducta antisocial: evaluación, tratamiento y prevención en la infancia y adolescencia. Madrid: Pirámide.

LeBlanc, M., Còte, G., \& Loeber, R. (1991). Temporal paths in delinquency: Stability, regression and progression analyzed with panel data from an adolescent and a delinquent male sample. Canadian Journal of Criminology, 1, 23-44.

Lerner, R., \& Steinberg, L. (2009). The scientific study of adolescent development. En R. M. Lerner \& L. Steinberg (Eds.), Handbook of adolescent psychology (3a. ed., pp. 3-14). Hoboken, NJ: Wiley.

Loëber, R., \& Farrington, D. P. (Eds.). (2001). Child delinquents: Development, 
intervention, and service needs. Thousand Oaks, CA: Sage.

Marsiglia, F., Kulis, S., Hecht, M., \& Sills, S. (2004). Ethnicity and ethnic identity as predictors of drug norms and drug use among preadolescents in the U.S. Southwest. Substance Abuse and Misuse, 39, 1061-1094.

Martínez, R., \& Dukes, R. (1997). The effects of ethnic identity, ethnicity, and gender on adolescent well-being. Journal of Youth and Adolescence, 26(5), 503-516.

Maynard, K., Coebergh, B., Anstiss, B., Bakker, L., \& Huriwai, T. (1999). 'Ki Te Arotu toward a new assessment: the identification of cultural factors which may pre-dispose Māori to crime'. Social Policy Journal of New Zealand, 13, 43-58.

Méndez, P., \& Barra, E. (2008). Apoyo social percibido en adolescentes infractores de ley y no infractores. Psykhe, 17(1), 59-64.

Moffitt, T. E. (1993). Adolescence-limited and life-course-persistent antisocial behavior: A developmental taxonomy. Psychological Review, 100(4), 674-701.

Monahan, K., Cauffman, E., \& Steinberg, L. (2009). Affiliation with antisocial peers, susceptibility to peer influence and antisocial behavior during the transition to adulthood. Developmental Psychology, 45 (6), 1520-1530.

Northoff, G., \& Heinzel, A. (2003). The self in philosophy, neuroscience and psychiatry: An epistemic approach. En A. David \& T. Kircher (Eds.), The self in neuroscience and psychiatry (pp. 40-55). Cambridge: Cambridge University Press.

Organización Internacional del Trabajo. (2006). Trabajo infantil y pueblos originarios en Chile. Experiencias en zonas aymara $y$ mapuche (Tarapacá y Araucanía). (Informe 14.02.2). Santiago: Autor. Recuperado de http://white.lim.ilo.org/ipec/boletin/doc umentos/pueblos_originarios_ch.pdf

Pegg, P., \& Plybon, L. (2005). Toward the theoretical measurement of ethnic identity. Journal of Early Adolescence, 25, 250-264.
Peña, M., \& Graña, J. (2006). Agresión y conducta antisocial en la adolescencia: una integración conceptual. Psicopatología Clínica, Legal y Forense, 6, 9-23.

Pérez-Luco, R., Alarcón, P., Zambrano, A., Alarcón, M., Lagos, L., Wenger, L., ... Reyes, A. (2014). MMIDA. Modelo Multidimensional de Intervención Diferenciada con Adolescentes. Vol. 1. Manual de intervención diferenciada: prácticas que transforman vidas. Temuco: Ediciones Universidad de La Frontera.

Pérez-Luco, R., Alarcón, P., Zambrano, A., Bustamante, G., \& Alarcón, M. (2009). Estrategia ecosistémica especializada de intervención diferenciada para favorecer la integración psicosocial de adolescentes infractores de ley (Proyecto FONDEF D08i-1205). Temuco: Universidad de La Frontera.

Pérez-Luco, R., Lagos, L., \& Báez, C. (2012). Reincidencia y desistimiento en adolescentes infractores: análisis de trayectorias delictivas a partir de autorreporte de delitos, consumo de sustancias y juicio profesional. Universitas Psychologica, 11(4). Recuperado de http://revistas.javeriana.edu.co/index.p hp/revPsycho/article/view/1209

Pérez-Luco, R., Lagos, L., Chesta, S., \& Báez, C. (2011). Escala de Delincuencia Autorrevelada "EDA". Instrumento de evaluación clínica del patrón delictivo adolescente (Proyecto FONDEF D08i-1205). Temuco: Universidad de La Frontera.

Piquero, A., \& Moffitt, T. E. (2005). Integrated developmental and life-course theories of offending: Advances in criminological theory. New Brunswick, NJ: Transactions Press.

Phinney, J. (1989). Stages of ethnic identity development in minority group adolescents. Journal of Early Adolescence, 9, 34-49.

Phinney, J. (1992). The Multigroup Ethnic Identity Measure: A new scale for use with adolescents and young adults from diverse 
groups. Journal of Adolescent Research, 7, 156-176.

Phinney, J., Cantu, C., \& Kurtz, D. (1997). Ethnic and American identity as predictors of selfesteem among African American, Latino, and White adolescents. Journal of Youth and Adolescence, 26(2), 165-185.

Phinney, J., \& Ong, A. (2007). Conceptualization and measurement of ethnic identity: Current status and future directions. Journal of Counseling Psychology, 54(3), 271-281.

Roberts, R., Phinney, J., Masse, L., Chen, Y., Roberts, C., \& Romero, A. (1999). The structure of ethnic identity in young adolescents from diverse ethnocultural groups. Journal of Early Adolescence, 19, 301-322.

Rojas, E., \& Gretton, H. (2007). Background, offences characteristics and criminal outcomes of Aboriginal youth who sexual offend: A closer look at Aboriginal youth intervention needs. Sex abuse: A journal of Research and Treatment, 19(3), 257-283. doi:10.1007/s11194-007-9048-1

Rugge, T. (2006). Risk assessment of male Aboriginal offenders: A 2006 perspective. (Informe 2006-01). Ottawa: Public Safety Canada.

Saint Louis, G., \& Liem, J. (2005). Ego identity, ethnic identity and the psychological wellbeing of ethnic minority and majority college students. International Journal of Theory and Research, 5(3), 227-246.

Saiz, J., Merino, M., \& Quilaqueo, D. (2009). Meta-estereotipos sobre los indígenas mapuche de Chile. Interdisciplinaria, 26(1), 23-48.

Saiz, J., Rapimán, E., \& Mladinic, A. (2008). Estereotipos sobre los mapuche: su reciente evolución. Psykhe, 17(2), 27-40.

Schwartz, S., Zamboanga, B., \& Hernández, L. (2007). Ethnic identity and acculturation in Hispanic early adolescents: Mediated relationships to academic grades, prosocial behaviors, and externalizing symptoms. Cultural Diversity and Ethnic Minority Psychology, 13(4), 364-373.
Servicio Nacional de Menores. (2010). Anuario Estadístico Institucional. Santiago de Chile: Autor. Recuperado de http://www.sename. $\mathrm{cl}$

Solís, M. A., \& Alvarado, A. (2014). Caracterización de los adolescentes infractores de ley de la región de Los Lagos: trayectorias delictivas y reincidencia (Tesis de maestría inédita). Universidad de La Frontera, Temuco.

Solís, A., Alvarado, A. y Pérez-Luco, R. (2015). Caracterización de la reincidencia delictiva de adolescentes infractores de ley de la Región de Los Lagos, Chile. Estudio epidemiológico y de trayectorias delictivas. Tesis de Magíster en Psicología Jurídica y Forense, Universidad de La Frontera, Temuco.

Steinberg, L., \& Sheffield, A. (2001). Adolescent development. Annual Review of Psychology, 52(1), 83-110.

Umaña-Taylor, A., \& Updegraff, K. (2007). Latino adolescents' mental health: Exploring the interrelations among discrimination, ethnic identity, cultural orientation, self-esteem, and depressive symptoms. Journal of Adolescence, 30(4), 549-567. doi:10.1016/ j.adolescence.2006.08.002

Van Meijl, T. (2008). Culture and identity in anthropology: Reflections on "unity" and "uncertaintly" in the dialogical self. International Journal for Dialogical Science, 3(1), 165-190.

Ward, T., \& Langlands, R. (2009). Repairing the rupture: Restorative justice and the rehabilitation of offenders. Aggression and Violent Behavior, 14(3), 205-214.

Wissinka, I., Dekovic M., Sengu, Y., Stamsb, G., $\&$ de Haana, M. (2008). Ethnic identity, externalizing problem behavior and the mediating role of self-esteem among Dutch, Turkish-Dutch and MoroccanDutch adolescents. Journal of Adolescence, 31, 223-240.

Yasui, M., Dorham, C., \& Dishion, T. (2004). Ethnic identity and psychological adjustment: A validity analysis for European American and African American 
Raúl Alberto Jiménez Bustos, Ricardo Xavier Pérez-Luco Arenas, Gonzalo Eugenio Bustamante Rivera.

adolescents. Journal of Adolescent Research, $19,807-825$.

\section{Notas}

* Artículo de investigación. 